Article

\title{
Psychometric of the Curiosity and Exploration Inventory-II in Indonesia
}

\author{
Anggi Setyowati, ${ }^{1}$ Min-Huey Chung, ${ }^{2,3}$ Ah. Yusuf, ${ }^{4}$ Setya Haksama ${ }^{5}$ \\ ${ }^{1}$ Public Health Faculty, Universitas Airlangga, Surabaya, Indonesia; ${ }^{2}$ School of Nursing, College of Nursing, \\ Taipei Medical University, Taipei, Taiwan; ${ }^{3}$ Department of Nursing, Taipei Medical University-Shuang Ho \\ Hospital, New Taipei City, Taiwan; ${ }^{4}$ Department of Community and Mental Health Nursing, Faculty of Nursing, \\ Universitas Airlangga, Surabaya, Indonesia; ${ }^{5}$ Department of Health Administration and Policy, Public Health \\ Faculty, Universitas Airlangga, Surabaya, Indonesia
}

\begin{abstract}
Background: Curiosity is a personality characteristic, which fits with wellbeing and positive functioning. The objective of this study was to assess the construct validity of the Curiosity and Exploration Inventory II (CEI-II) in Indonesia.

Design and Methods: The study included 256 undergraduate students who lived in Indonesia, mean age 19.8 years old. The CEI-II measures stretching and embracing using 11 items. The English version of CEI-II was translated into Bahasa. The Cronbach's alpha coefficient and intraclass correlation coefficient (ICC) were addressed to examine internal consistency reliability and the test-retest reliability. To evaluate construct validity, exploratory factor analysis (EFA) was used to assess factor structure and confirmatory factor analysis (CFA) was used to evaluate the structural model fit of the CEI-II Indonesia version.

Results: The study showed Cronbach's alpha for the internal consistency of the overall CEI-II Indonesia version was 0.77 . The ICC for the test-retest reliability ranged between $0.753-0.829$. EFA showed adequate with the Kaiser-Meyer-Olkin value of 0.86 and the Bartlett's test of sphericity was statistically significant. CFA tested the second-order model with two-order factors and showed a model fit.

Conclusions: The CEI-II Indonesia version indicated acceptable construct validity to evaluate curiosity in Indonesia.
\end{abstract}

\section{Introduction}

Curiosity is a personality characteristic, which fits with wellbeing and positive functioning. ${ }^{1}$ It also relates to life satisfaction, meaningful life $^{2}$ and creativity ${ }^{3}$. Curiosity has been conceptualized as an individual desire to look for something new, ${ }^{4}$ cognition, ${ }^{5}$ self-regulation as well as positive emotional-motivational system. ${ }^{6}$

Curiosity is needed to stimulate children's and adolescents' development ${ }^{5,7}$ because they can then explore what attracts their interests $^{7}$ and affects their behavior to seek information. ${ }^{1}$ This behavior must develop during early childhood to enhance learning in adults ${ }^{8,9}$ trigger motivation, and it relates to problem solving. ${ }^{5}$ Furthermore, curiosity is important in the classroom, especially for students to understand something. ${ }^{7,10}$ Previous study mentioned that students in Indonesia show low motivation as well as creating ideas in the class. ${ }^{11}$ Therefore, we need a tool to understanding and measure curious in research purpose, ${ }^{12}$ so reliable data can be used to enhance learning in Indonesian students.

There are several instruments to measure curiosity; $4,6,13,14$ one of such tools that has been used over the last decade is the Curiosity and Exploration Inventory (CEI) designed by Kashdan et al. ${ }^{6}$ However, a few limitations have been found in CEI, such as the fact that it is negatively worded and exhibited failed construct validity. ${ }^{14,15}$ Therefore, CEI was developed into CEI-II. CEI-II has stable reliability among college students. ${ }^{14,15,16}$ CEI-II includes two subscales: stretching or exploration, which refers to the motivation to look for knowledge, and embracing, which refers to the willingness to embrace newness. ${ }^{14}$ The validation of CEI-II is conducted in Chinese, Romanian, and English. ${ }^{14,15,16}$ It is also available in several other languages, such as Spanish, Chinese, Italian, German, Russian, French, Norwegian, Portuguese, Finnish, Persian, Dutch, Hungarian, Slovak, and Czech. ${ }^{17}$ Thus, The CEI-II showed satisfactory reliability and validity.

The CEI-II has not been provided in Bahasa and, as far as we know, the construct validity has not been conducted among undergraduate students in Indonesia. Therefore, this study is aimed to translate and evaluate the construct validity of the Indonesian CEI-II version.

Significance for public health

Curiosity is associated with higher life satisfaction as well as subjective well-being. The National Prevention, Health Promotion, and Public Health Council, United States mentioned subjective well-being as 1 of 7 priority areas for the National Prevention Strategy to improve physical and mental functioning. Curiosity has been conceptualized as an individual desire to look for something new, cognition, and self-regulation. It is considered as an important role in human development. Furthermore, we need tool to improve understanding and measure curiosity in undergraduate students. A tool is required in clinical and research purpose to rapid screening on a large scale and to provide reliable data, especially considering that curiosity is one of indicator of well-being. This study aimed to assess psychometric of Curiosity and Exploration Inventory II (CEI-II), so the undergraduate students can be aware of their positive emotional-motivational system as well as their personality. The result showed the CEI-II Indonesia version indicated acceptable construct validity to evaluate curiosity in Indonesia. 


\section{Design and Methods}

This research was granted by the Ethics Research Committee from University Tunku Abdul Rahman, Malaysia, in March 2017. All of the participants agreed to join this study and provided online written informed consent; they were allowed to withdraw during this study and this study was also anonymous and voluntary.

This study used cross-sectional design and online self-report questionnaire using Qualtrics Survey Software and Google Form and it was conducted from February until May 2017. Data were collected from 256 undergraduate students who lived in Indonesia, from two public universities in Java Island and two nursing schools in Kalimantan Island. It used purposive sampling, and inclusion criteria were being undergraduate students, full-time or part-time study, and all gender could participate in this study. Previous study suggested minimum sample size of 200 to produce adequate statistics. ${ }^{18} \mathrm{We}$ evaluated test-retest reliability of the CEIII Indonesian version from 30 participants who repeated the answers of the CEI-II Indonesian version twice at two-week intervals.

CEI-II was designed to measure two factors. The first is stretching, which refers to motivation to look for new experience and knowledge, whereas the second factor is embracing, which refers to willingness to deal with new, uncertain, and unpredictable events in life. The CEI-II contains 10 items. Each item uses a 5point Likert scale (1: very slightly or not at all, 5: extremely). Higher score indicates high curiosity. ${ }^{14}$ The CEI-II has been measured to be valid and reliable for assessing individual degree in the recognition, pursuit, and dealing with new experience and knowledge. The CEI-II has adequate internal reliability (Cronbach's alpha 0.86-0.90). ${ }^{14,15}$

SPSS for Windows was used to analyze the data. To examine the CEI-II, descriptive statistics were computed as minimal and maximal values, mean, standard deviation (SD), skewness, and kurtosis. Skewness is the degree of asymmetric data, adequate skewness score range is between -1 to $1 .{ }^{19}$ Likewise, kurtosis is used to measure the peakedness of data distribution, and a value of kurtosis less than 2.5 times the standard error indicates normal data. ${ }^{19,20}$ Inter-item correlation and item-total correlation were calculated using Pearson correlation; a correlation more than 0.2 indicates satisfactory. ${ }^{21}$ The internal consistency reliability was measured using Cronbach's alpha: previous studies suggest that Cronbach's alpha $>0.5$ is considered acceptable reliability. ${ }^{22,23}$ The intraclass correlation coefficient (ICC) was used to examine twoweek test-retest reliability of CEI-II. Acceptable test-retest reliability was greater than $0.75 .{ }^{24}$

Exploratory factor analysis (EFA) using principal axis factoring with varimax rotation was used to evaluate construct validity. ${ }^{25}$ Factor analysis was selected by Kaiser-Meyer-Olkin (KMO) and Bartlett's test of sphericity. ${ }^{26} \mathrm{KMO}$ must be greater than 0.6 and the Bartlett's test value of sphericity must be significant $(\mathrm{p}<0.001) .{ }^{27,28}$ The criteria for measuring the number of factors extraction use the following criteria: eigenvalue $>1^{29}$ and the percentage of variance explained is $\leq 50-60 \% .{ }^{27,30}$ Convergent validity was evaluated by several indicators; i) factor loading, each item must be greater than $0.32 ; 31$ ii) the composite reliability (CR) of dimension must be greater than $0.7 ; 27$ iii) average variance extracted (AVE) is higher than 0.5 ; however, AVE more than 0.4 is still accepted if CR is more than 0.6.32

Confirmatory factor analysis (CFA) was used to assess the structural model fit of CEI-II. AMOS software version 21.0 was used to test the goodness of fit. The following fit indices were evaluated: chi squared/ $d f$ (the ratio of the chi square to the degree of freedom), normed fit index (NFI), goodness of fit index (GFI), adjusted goodness-of-fit index (AGFI), comparative fit index (CFI), and related fit index (RFI) should be greater than $0.90^{33}$ and root-mean-square error of approximation (RMSEA) should be lower than 0.1 , because RMSEA greater than 0.1 indicates poor values. ${ }^{34}$ Discriminant validity was assessed by two criteria: i) correlation coefficient between dimensions of less than 1 ; ii) the correlation coefficient of the dimension being less than the individual Cronbach's alpha coefficient. ${ }^{35}$ Second order model was conducted to assess validity ${ }^{36}$ and estimates the effect of the main construct on the sub construct. ${ }^{37}$

\section{Results}

Table 1 shows the characteristic of the participants, including age and gender. Table 2 shows this study included 256 undergraduate students with a mean (SD) age of 19.81 (1.62) and ranging in age from 17 to 26 years. Most of the participants were female students $(65.6 \%)$. A further 30 participants were undergraduate students with a mean (SD) 20.3 (0.53) years and most participants were female students $(83.3 \%)$

\section{Reliability}

Table 3 shows the Cronbach's alpha coefficient of the overall CEI-II Indonesian version was 0.767 , and that, for each item, ranged from $0.724-0.804$. The intraclass correlation coefficient (ICC) ranged between $0.753-0.829$. There was statistically significant and positive correlation between the global score CEI-II Indonesian version and the 10-item scores of the CEI-II Indonesian version. The range correlation between each item was $\mathrm{r}=0.286$ $0.715, \mathrm{p}<0.05$.

\section{Factor structure of the CEI-II}

Exploratory factor analysis (EFA) was performed before conducting the construct validity. EFA was used to analyze all 10 items

Table 1. Characteristics of participants $(n=256)$.

\begin{tabular}{|c|c|c|c|c|c|c|}
\hline \multirow[b]{2}{*}{ Characteristics } & \multicolumn{3}{|c|}{ Participants for construct validity $n=256$} & \multicolumn{3}{|c|}{ Participants for test-retest reliability $n=30$} \\
\hline & Mean (SD) & n & $\%$ & Mean (SD) & n & $\%$ \\
\hline Age (years) & $19.81(1.62)$ & & & $20.3(0.53)$ & & \\
\hline \multicolumn{7}{|l|}{ Gender } \\
\hline Male & & 88 & 34.4 & & 5 & 16.7 \\
\hline Female & & 168 & 65.6 & & 25 & 83.3 \\
\hline
\end{tabular}


of the CEI-II. Table 4 shows the value of the Kaiser-Meier-Olkin test was 0.86 and the Bartlett's test value of sphericity was statistically significant $(\mathrm{p}<0.001)$. In addition, two factors were retained based on eigenvalues. Both factors had eigenvalues greater than 1 . All of the items in the CEI-II Indonesian version had factor loading greater than 0.32 , which indicates favorable convergent validity. The first factor consists of six items (Item 1, 3, 4, 5, 7, and 9) and refers to stretching or motivation to seek out knowledge and new experience, yielding $36.769 \%$ explained variance. The second factor consists of four items (Item 2, 6, 8, and 10) and refers to embracing or willingness to deal with new, uncertain, and unpredictable events in life; it yields $12.697 \%$ explained variance.

\section{Construct validity}

Table 3 shows the CR score for stretching was 0.837 and for embracing was 0.717 . The AVE's two constructs were 0.468 and 0.4 , respectively, which indicated acceptable convergent validity. Confirmatory Factor Analysis (CFA) was conducted to validate the structure of CEI-II Indonesian version with second order. Figure 1 presents the goodness of fit for the model structure with $\chi 290.156$ $(\mathrm{df}=34, \mathrm{p}=0.00)$; goodness-of-fit index $(\mathrm{GFI})=0.936$, adjusted goodness-of-fit index $(\mathrm{AGFI})=0.897$, comparative fit index $(\mathrm{CFI})=0.909$, root-mean-square error of approximation $($ RMSEA $)=0.08$, normed fit index $(\mathrm{NFI})=0.864$, and related fit index $(\mathrm{RFI})=0.819$.

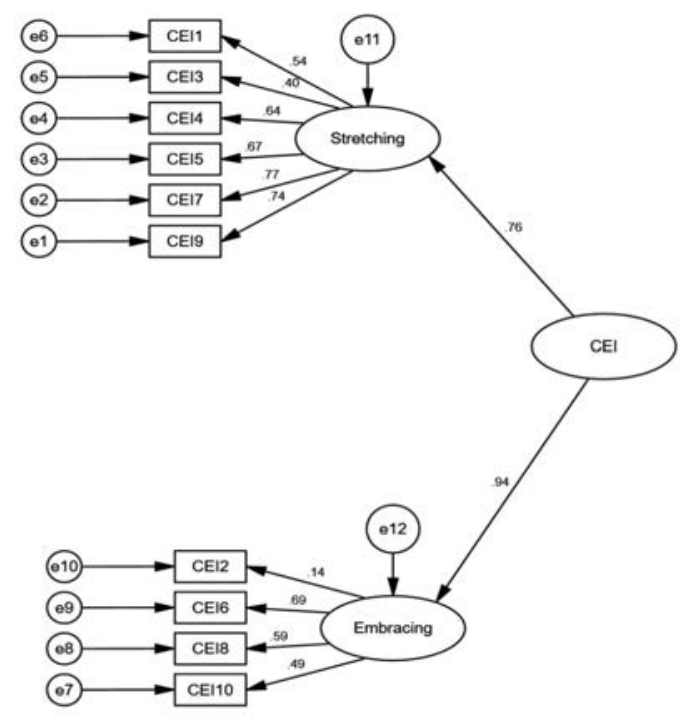

Figure 1. The factor structure of CEI-II. Model fit index: $X 2$ $90.156(\mathrm{df}=34, \mathrm{p}=0.00)$; goodness-of-fit index $(\mathrm{GFI})=0.936$, adjusted goodness-of-fit index $(\mathrm{AGFI})=0.897$, comparative fit index $(\mathrm{CFI})=0.909$, root-mean-square error of approximation $($ RMSEA $)=0.08$, normed fit index $(\mathrm{NFI})=\mathbf{0 . 8 6 4}$, related fit index $(\mathrm{RFI})=0.819$.

Table 2. Average scores of the CEI-II in the Indonesian language according to items and dimensions.

\begin{tabular}{|c|c|c|c|c|c|c|c|}
\hline SEI-II & le itt & $\operatorname{Min}$ & Max & Mean & SD & kewness & Kurtosis \\
\hline I actively seek as much information as I can in new situations & Item 1 & 1.00 & 5.00 & 3.84 & 0.77 & -0.447 & 0.583 \\
\hline I am the type of person who really enjoys the uncertainty of everyday life & Item 2 & 1.00 & 5.00 & 2.17 & 1.14 & 0.503 & -0.894 \\
\hline I am at my best when doing something that is complex or challenging & Item 3 & 1.00 & 5.00 & 3.77 & 0.80 & -0.774 & 1.222 \\
\hline Everywhere I go, I am out looking for new things or experiences & Item 4 & 1.00 & 5.00 & 4.03 & 0.76 & -0.516 & 0.280 \\
\hline I view challenging situations as an opportunity to grow and learn & Item 5 & 2.00 & 5.00 & 4.05 & 0.76 & -0.397 & -0.365 \\
\hline I like to do things that are a little frightening & Item 6 & 1.00 & 5.00 & 3.44 & 0.98 & -0.264 & -0.141 \\
\hline I am always looking for experiences that challenge how I think about myself and the world & Item 7 & 1.00 & 5.00 & 3.74 & 0.93 & -0.699 & 0.437 \\
\hline I prefer jobs that are excitingly unpredictable & Item 8 & 1.00 & 5.00 & 3.30 & 1.13 & -0.408 & -0.445 \\
\hline I frequently seek out opportunities to challenge myself and grow as a person & Item 9 & 1.00 & 5.00 & 3.36 & 0.90 & -0.604 & 0.384 \\
\hline I am the kind of person who embraces unfamiliar people, events, and places & Item 10 & 1.00 & 5.00 & 3.39 & 1.09 & -0.453 & -0.169 \\
\hline
\end{tabular}

Min, minimum; Max, maximum; SD, standard deviation.

Table 3. Correlation coefficients of the items CEI-II conforming to extracted factors after varimax rotation.

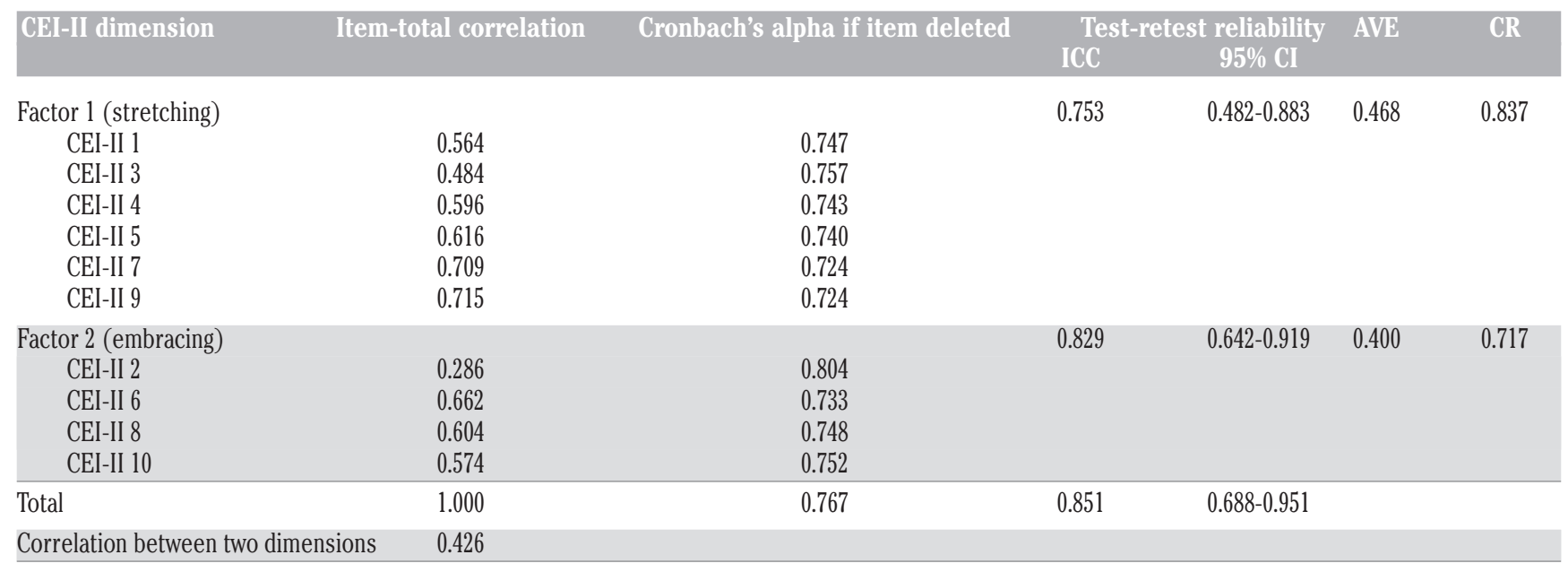




\section{Discussion}

The aim of this study was to assess the construct validity as well as reliability of the CEI-II Indonesian version. The result of internal consistency for Indonesian undergraduate students had adequate internal consistency (Cronbach's alpha $=0.77$ ). In addition, researchers evaluated the various CEI-II questionnaires in different language versions and found an acceptable Cronbach's alpha between $0.79-0.90 .6,15,16$ In line with previous studies, Cronbach's alpha $>0.5$ was acceptable. ${ }^{22,23}$ Table 3 show that the test-retest correlation coefficient had temporal stability for two dimensions. The results of ICC ranged from 0.753-0.829, and embracing had the highest score. Previous study addressed that acceptable test-retest reliability was greater than $0.75 .{ }^{24}$ In this study the Cronbach's alpha and the correlation coefficient were of acceptable value, so it showed that CEI-II was a stable instrument to measure curiosity.

The CEI-II Indonesian version was supported by construct validity. Exploratory factor analysis was used to extract two CEIII factors from 10 items in this questionnaire. There was a change in the factor structure, compared with the original version of CEIII; however, all items of the CEI-II Indonesian version had factor loadings greater than 0.32 . This indicates that CEI-II has acceptable convergent validity. ${ }^{31}$ In the process of exploratory factor analysis of the CEI-II Indonesian version, the first factor, stretching, produced six items, similar to the original CEI-II, except item 4 everywhere I go, I am out looking for new things or experiences. So, the second factor, embracing, produced the remaining four items. Factor analysis produces different dimensions, in some population, due to phrases that are used. ${ }^{37}$ The translation of item 4 in Bahasa is similar to stretching, which refers to the motivation to look for knowledge.

This study employed CFA to examine the construct validity of the CEI-II. Adequate convergent validity was shown by the results of AVE and CR (Table 3). The model structure was measured based on several fit indices, specifically GFI, AGFI, CFI, RFI, NFI, and RMSEA. In this study, the value of the RMSEA was 0.08 . The RMSEA was used to evaluate the model and it is recommended that the score is less than $0.1{ }^{34}$ Figure 1 shows that the value of the RMSEA in this study was 0.08 , which indicates an adequate model structure for the two factors. Factor loading of all factors of the CEI-II showed significant factor loading from $0.43-0.78$. We

Table 4. Correlation coefficients of the items CEI-II conforming to extracted factors after varimax rotation.

\begin{tabular}{ccc} 
& Items & Factor loading \\
Stretching & & \\
CEI-II 1 & 0.614 & \\
CEI-II 3 & 0.434 & \\
CEI-II 4 & 0.725 & \\
CEI-II 5 & 0.780 & \\
CEI-II 7 & 0.765 & \\
CEI-II 9 & 0.725 & \\
Embracing & & \\
CEI-II 2 & & 0.673 \\
CEI-II 6 & & 0.625 \\
CEI-II 8 & & 0.695 \\
CEI-II 10 & & 1.269 \\
\hline Eigen value & 3.677 & 12.697 \\
Cumulative variance explained & 36.769 & \\
\hline
\end{tabular}

performed a second-order model to obtain optimal goodness of fit.

The limitations of this study were that the self-report questionnaire caused bias and we only focused on construct validity, so we did not compare the Indonesian version of CEI-II to other scales that measure personality related to curiosity constructs.

\section{Conclusions}

Despite these limitations, our study addressed that the CEI-II Indonesian version supported construct validity to measure curiosity. The CEI-II consists of 10 items related to stretching and embracing and it is suitable to detect curiosity among students in Indonesia, which fits with wellbeing.

Correspondence: Ah. Yusuf, Department of Community and Mental Health Nursing, Faculty of Nursing, Universitas Airlangga, Surabaya, Indonesia. Tel. +62.8123298571- Fax: +62.315913752.

E-mail: ah-yusuf@fkp.unair.ac.id

Key words: Evaluation; curiosity; construct validity; Indonesia.

Acknowledgements: We would like to thank the teachers of the University for their friendly support.

Contributions: All the authors contributed equally.

Conflict of interest: The authors declare no conflict of interest Funding: The work was supported by Universitas Airlangga

Clinical trials: The study is not involved any clinical trial.

Ethics approval and consent to participate: This research was granted by the Ethics Research Committee from University Tunku Abdul Rahman, Malaysia in March 2017. All of the participants agreed to join this study and provided online written informed consent; they were allowed to withdraw during this study and this study was also anonymous and voluntary.

Received for publication: 7 February 2020

Accepted for publication: 24 July 2020

(c) Copyright: the Author(s), 2020

Licensee PAGEPress, Italy

Journal of Public Health Research 2020;9:1745

doi:10.4081/jphr.2020.1745

This work is licensed under a Creative Commons Attribution NonCommercial 4.0 License (CC BY-NC 4.0).

\section{References}

1. Jovanović V, Gavrilov $\square$ Jerković V. The good, the bad (and the ugly): The role of curiosity in subjective well $\square$ being and risky behaviors among adolescents. Scandinavian J Psychol 2014;55:38-44.

2. Silvia PJ, Kashdan TB. Interesting things and curious people: Exploration and engagement as transient states and enduring strengths. Soc Personal Psychol Compass 2009;3:785-97.

3. Karwowski M. Did curiosity kill the cat? Relationship between trait curiosity, creative self-efficacy and creative personal identity. Eur J Psychol 2012;8:547-58. 
4. Litman JA, Silvia PJ. The latent structure of trait curiosity: Evidence for interest and deprivation curiosity dimensions. J Pers Assess 2006;86:318-28.

5. Bowler L. The self $\square$ regulation of curiosity and interest during the information search process of adolescent students. J Am Soc Inf Sci Technol 2010;61:1332-44.

6. Kashdan TB, Rose P, Fincham FD. Curiosity and exploration: Facilitating positive subjective experiences and personal growth opportunities. J Pers Assess 2004;82:291-305.

7. Engel S. Children's need to know: Curiosity in schools. Harv Educ Rev 2011;81:625-45.

8. Fandakova Y, Gruber M. Curiosity and surprise enhance memory differently in adolescents than in children. PsyARXiv 2019.

9. Lindholm M. Promoting Curiosity? Sci Educ 2018;27:9871002.

10. Binson B. Curiosity-based learning (CBL) program. US-China Educ Rev 2009;6:13-22.

11. Asmin AI. Observing the intellectual curiosity of English education students in the class. IDEAS 2020;8:1263.

12. Ramirez SZ, Lukenbill J. Psychometric properties of the Zung self-rating anxiety scale for adults with intellectual disabilities (SAS-ID). J Dev Phys Dis 2008;20:573-80.

13. Collins RP, Litman JA, Spielberger CD. The measurement of perceptual curiosity. Pers Individ Differ 2004;36:1127-41.

14. Kashdan TB, Gallagher MW, Silvia PJ, et al. The curiosity and exploration inventory-II: Development, factor structure, and psychometrics. J Res Personal 2009;43:987-98.

15. Ye S, Ng TK, Yim KH, Wang J. Validation of the Curiosity and Exploration Inventory-II (CEI-II) among Chinese university students in Hong Kong. J Pers Assess 2015;97:403-10.

16. Balgiu BA. Psychometric Properties of Curiosity and Exploration Inventory-II (CEI-II) in the Case of A Sample of Romanian Students. Rev de Psihol 2018;64:102-14.

17. Kashdan TB. Measures 2019. Accessed on: 15 October 2019. Available from: https://www.toddkashdan.com/measures/

18. Quintana SM, Maxwell SE. Implications of recent developments in structural equation modeling for counseling psychology. Couns Psychol 1999;27:485-527.

19. Chan Y. Biostatistics 101: data presentation. Singapore Med J 2003;44:280-5.

20. Ladi JS, Shah NA. Comparison of central corneal thickness measurements with the Galilei dual Scheimpflug analyzer and ultrasound pachymetry. Indian J Ophthalmol 2010;58:385.

21. Kline P. A Handbook of Test Construction: Introduction to
Psychometric Design. New York: Methuen. Inc; 1986.

22. Morera OF, Stokes SM. Coefficient $\alpha$ as a measure of test score reliability: Review of 3 popular misconceptions. Am J Public Health 2016;106:458-61.

23. Streiner DL. Starting at the beginning: an introduction to coefficient alpha and internal consistency. J Pers Assess 2003;80:99-103.

24. Koo TK, Li MY. A guideline of selecting and reporting intraclass correlation coefficients for reliability research. J Chirop Med 2016;15:155-63.

25. Indrayan A, Holt MP. Concise encyclopedia of biostatistics for medical professionals. CRC Press; 2016.

26. Coates S, Steed L. Spss for Windows: Analysis without anguish Milton. Queensland: Jacaranda Willey; 1996.

27. Hair JF, Anderson RE, Babin BJ, Black WC. Multivariate data analysis: A global perspective (Vol. 7). Upper Saddle River: Pearson; 2010.

28. Tabachnick BG, Fidell LS, Ullman JB. Using multivariate statistics. Boston: Pearson; 2007.

29. Kaiser HF. The application of electronic computers to factor analysis. Educ Psychol Meas 1960;20:141-51.

30. Pett MA, Lackey NR, Sullivan JJ. Making sense of factor analysis: The use of factor analysis for instrument development in health care research. Thousands Oaks: Sage; 2003.

31. Comrey A, Lee H. A first course in factor analysis. Hillsdale, NJ: Erlbaum; 1992.

32. Huang CC, Wang YM, Wu TW, Wang PA. An empirical analysis of the antecedents and performance consequences of using the moodle platform. Int J Inf Educ Technol 2013;3:217.

33. Hair JF, Black WC, Babin BJ, et al. Multivariate data analysis. Upper Saddle River: Prentice Hall; 1998.

34. Norris M, Lecavalier L. Evaluating the use of exploratory factor analysis in developmental disability psychological research. J Autism Dev Dis 2010;40:8-20.

35. Gaski JF, Nevin JR. The differential effects of exercised and unexercised power sources in a marketing channel. J Mark Res 1985;22:130-42.

36. Kohring M, Matthes J. Trust in news media: Development and validation of a multidimensional scale. Comm Res 2007;34:231-52.

37. Youn S, Kim C, Lee J, et al. Development of dysfunctional beliefs and attitude about sleep scale for cancer patients. Behav Sleep Med 2020;18:287-97. 